\title{
Assessing Road Safety Performance by Data Envelopment Analysis - The Case of Brazil
}

\author{
Jorge Tiago BASTOS ${ }^{1,2}$, Yongjun SHEN $^{2}$, Elke HERMANS ${ }^{2}$, Tom BRIJS, Geert \\ WETS $^{2}$ and Antonio Clóvis FERRAZ ${ }^{1}$
}

${ }^{1}$ Department of Transportation Engineering, School of Engineering of São Carlos, University of São Paulo, Av. Trabalhador São-carlense 400, São Carlos, 13566590; $\mathrm{PH}+55$ 16-33739601 911-1234; FAX +55 16-3373-9602; E-Mail: jtbastos@usp.br, coca@sc.usp.br

${ }^{2}$ Transportation Research Institute (IMOB), Wetenschapspark 5 Bus 6, Diepenbeek, 3590, Belgium; PH +32 11 269111; FAX +32 11 269199; E-Mail: yongjun.shen@uhasselt.be, elke.hermans@uhasselt.be, tom.brijs@uhasselt.be, geert.wets@uhasselt.be

\begin{abstract}
The intense economic growth experienced by Brazil in recent decades and its consequent explosive motorization process have generated an undesirable impact: the increasing and unbroken trend in road traffic fatalities. In order to contribute to road safety diagnosis, this study presents a research on two main available indicators in Brazil: mortality rate (represented by fatalities per inhabitants); and fatality rate (represented by two sub-indicators, i.e., fatalities per vehicle and fatalities per vehicle kilometers traveled). These indicators were aggregated into a composite indicator (CI) through a multiple layer data envelopment analysis CI model (ML DEA-CI), in which the optimum combination of indicators' weights is searched for each decision-making unit (DMU), in this case, the 27 Brazilian states (BR-27). The composite indicator represents the road safety performance on which a ranking of states can be made. As a result, valuable differences associated to DMU's socioeconomic attributes were outlined after calibrating the model.
\end{abstract}

\section{INTRODUCTION}

According to the most recent Global Status Report on Road Safety, the overall number of traffic fatalities has reduced from 2007 to 2010, a period in which 88 countries managed to decrease the total number of fatalities on their road system (World Health Organization, 2013). However, approximately the same quantity of countries presented an increase on traffic fatalities; in this context, the middleincome countries, where motorization is a fast-ongoing process, manifest as the 
nations with the highest risk on traffic. Brazil, the largest economy in Latin America, is typical of this group. The negative impacts of this motorization process are reflected in the increasing and unbroken trend in the number of traffic fatalities: in 2011, it amounted to more than 43,000 -identified according to the $10^{\text {th }}$ revision of the International Classification of Diseases (Ministério da Saúde, 2013a).

In order to bring a contribution to the field, this paper describes a first approach on applying a data envelopment analysis tool to assess the road safety situation in Brazilian states. The subject is carried out according to the following steps: (1) the combination of traffic fatality indicators into a composite indicator and posterior ranking of Brazilian states; (2) preliminary results interpretation based on the European results; (3) model calibration; and (4) final ranking assessment.

\section{TRAFFIC FATALITY INDICATORS}

The most commonly used indicators to express the road safety situation of geographical areas (i.e., countries, states or cities) are formed by the ratio between a certain type of outcome and an exposure measure. Here, the outcome is considered as the undesirable consequence of the phenomenon under investigation: the traffic fatality. As the ratio denominator, four exposure measures are most frequently considered (Elvik et al., 2009; Jørgensen, 2006): (I) number of inhabitants; (II) number of motor vehicles; (III) number of traveled kilometers; and (IV) number of passenger kilometers.

Here, the indicator I is referred to as "mortality rate" (MR), for example as by the Institute for Road Safety Research (2013). In quite general terms, the indicators II, III, and IV provide the same information in three different refinement levels regarding the definition of the risk exposure parameter. This second group of indicators are referred here as "fatality rate" (FR), a term adopted in this study and also in Hermans (2009).

Whatever a traffic death indicator is adopted, it is important to interpret it under the delimitated perspective provided by the denominator; yet, in practice, they are all used to perform road safety evaluations without proper appraisal regarding this topic, especially in developing countries. Decision makers must carefully manage both theoretical recommendations and data availability restrictions on the choice of the indicator to be used in each evaluation context; otherwise erroneous or at least inaccurate conclusions may arise. The investigation of strategies capable of delivering an overall picture of the situation through the combination of indicators, without focusing on only one indicator scope, is a valuable work to be conducted. In this sense, the data envelopment analysis technique is presented in the upcoming section as an alternative to manage this dilemma. 


\section{DATA ENVELOPMENT ANALYSIS}

Data envelopment analysis (DEA) is a term used to designate a "data oriented" approach in which mathematical programming methods are applied to handle large number of variables and relations between inputs and outputs. The entities under study, responsible to convert inputs into outputs, are named as decision making units (DMUs) (Cooper et al., 2000). The efficiency of a DMU usually varies between 0 and 1 , with the first value corresponding to the most inefficient and the second value to the most efficient DMU. In other words, a DMU with a score equal to 1 is capable of converting all its inputs into outputs (output/input ratio equal to one); in contrast, an inefficient DMU will not succeed in converting all its inputs into outputs and its output/input ratio will not reach one.

In the road safety framework, this technique has been applied for both inputoutput data sets (Hermans et al., 2009; Shen et al., 2011) and composite indicator research, the area in which this paper is situated (Bax et al., 2012; Shen et al., 2010). The model presented in Equation 1 is a converted form of the original model, in which each particular indicator is referred as an output to be minimized (Cherchye et al., 2006), because in road safety research, fatalities are undesirable outputs. The scores indicating the best performers will present a value equal to 1 (as in the original model). The difference now is that underperforming DMUs will present a score larger than 1 , since they did not succeed in minimizing their undesired outcome values.

$$
\text { OIS } S_{s}=\min \sum_{i=1}^{p} w_{i} y_{i, s} \quad \text { subject } \quad \text { to } \quad \sum_{i=1}^{p} w_{i} y_{i, s} \geq 1, \quad s=1, \square, n \quad w_{i} \geq 0, \quad i=1, \square, p
$$

$O I S_{s}$ is the Optimum Index Score (or composite indicator, CI, value) of the $s$ th DMU, $y_{i, s}$ is the $i$-th indicator of the $s$-th DMU, $w_{i}$ is the weight attributed to indicator $y, n$ is the total number of DMUs and $p$ the total number of indicators. For some practical real and complex problems, it might be helpful to describe the issue under investigation in terms of its different categories linked in a multilayer hierarchy. It motivated the development of the multiple layer DEA-based composite indicator model (ML DEA-CI) (Shen et al., 2013). By solving Equation 2, the composite indicator based on a $K$-layered hierarchy of $p$ indicators can be calculated, where $u_{f K}$ is the weight given to the $f$-th category in the $K$-th layer and $p_{f K}{ }^{(K)}$ denotes the non-negative internal weights associated with the indicators of the $f$-th category in the $K$-th layer; the sum of all $p_{f K}^{(K)}$ within a particular category is equal to one.

$$
\text { OIS } S_{s}=\max \sum_{f_{K_{1}}=1}^{p^{(K)}} u_{f_{K}}\left(\sum_{f_{K-1} \in A_{K}^{(K)}} w_{K-1}^{(K-1)}\left(\square \sum_{f_{k} \in A_{k+1}^{(k+1)}} w_{k}^{(k)}\left(\square \sum_{f_{k-1} \in A_{f_{3}}^{(3)}} w_{2}^{(2)}\left(\sum_{f_{1} \in A_{f_{2}}^{(2)}} w_{f_{1}}^{(1)} y_{f_{1} s}\right)\right)\right)\right)
$$


Finally, a distinction still has to be made between the optimum index score (OIS) and the cross-index score (CIS). The first must be used to identify the best performing DMUs among all the other assessed DMUs; however, the flexibility in selecting the most favorable weights for each DMU forbids the comparison on a common basis. The CIS, used for a direct comparison, is obtained from the OIS through using an average value of the product between each DMU indicator and not only its own attributed weights, but also all the other DMUs' weights (Doyle and Green, 1994), as in Equation 3.

$$
C I S_{s}=(1 / n) \sum_{s=1}^{n} \sum_{i=1}^{p}\left(w_{i} y_{i, s}\right)
$$

\section{DATA SETS}

Due to the continental dimension of Brazil, national values cannot be generalized, since each region or state might exhibit very contrasting figures. This section brings a "per state" disaggregated picture of road safety situation and also of the socioeconomic context (linked to road safety). Brazil contains 27 member states, herein generically referred as BR-27. This set includes Paraná (PR), Rio Grande do Sul (RS) and Santa Catarina (SC) - Southern states; Espírito Santo (ES), Minas Gerais (MG), Rio de Janeiro (RJ) and São Paulo (SP) - Southeastern states; Distrito Federal (DF), Goiás (GO), Mato Grosso (MT) and Mato Grosso do Sul (MS) Center-Western states; Alagoas (AL), Bahia (BA), Ceará (CE), Maranhão (MA), Paraíba (PB), Pernambuco (PE), Piauí (PI), Rio Grande do Norte (RN) and Sergipe (SE) - Northeastern states; and Acre (AC), Amapá (AP), Amazonas (AM), Pará (PA), Rondônia (RO), Roraima (RR) and Tocantins (TO) - Northern states.

The regions division is the most commonly used due to its coincident with the state borderlines (Instituto Brasileiro de Geografia e Estatística, 1970). The former division in macro regions is based on historical characteristics and economic integration (Geiger, 1969). The Center-South is constituted by the Southern-, Southeastern-, and Center-Western-most integrated regions; this is the most urbanized and developed area of the country. The Northeast is characterized by the contrast between the more urbanized and touristic coastal areas and the interior with low population density and historic social problems due to the semi-arid climate. The Amazon is characterized by low population density, containing more intense human occupation only in isolated areas (predominantly in the states capital cities). Figure 1 presents the location of BR-27, including regional and geo-economic divisions of the country. 


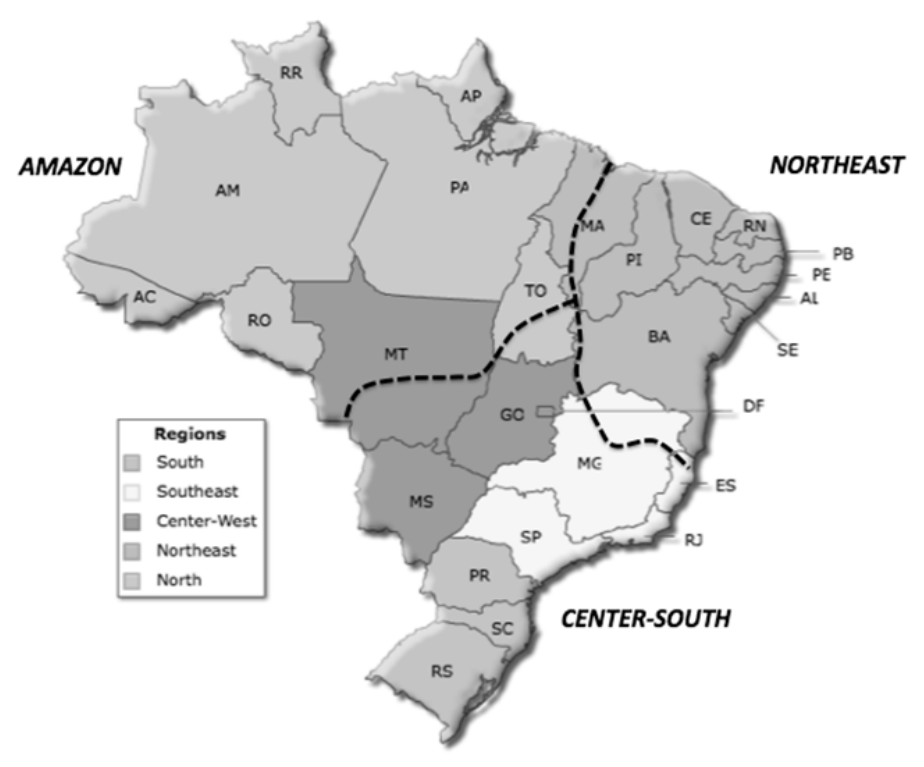

Figure 1. BR-27 states, regional and geo-economic division (dashed black line).

Regarding the European Union data set, the 27 member states considered were Austria (AT), Belgium (BE), Bulgaria (BG), Cyprus (CY), Czech Republic (CZ), Denmark (DK), Estonia (EE), Finland (FI), France (FR), Germany (DE), Greece (EL), Hungary (HU), Ireland (IE), Italy (IT), Latvia (LV), Lithuania (LT), Luxembourg (LU), Malta (MT), the Netherlands (NL), Romania (RO), Poland (PL), Portugal (PT), Slovakia (SK), Slovenia (SI), Spain (ES), Sweden (SE), and United Kingdom (UK). The more mature experience on this study field concerning the set of European Union countries, herein referred to as EU-27, enables it to be used as a reference to evaluate the inedited application with Brazilian data.

An equivalent data set was collected for BR-27 and EU-27, in which the three considered indicators are mortality rate (MR), fatalities per 100 thousand inhabitants; and two fatality rates - fatalities per 10 thousand vehicles (FR1) and fatalities per billion vehicle kilometers traveled (FR2), in the case of Brazil, or per billion passenger vehicle kilometers traveled (FR2), in the case of Europe. Table 1 presents the three indicators' average values in the period 2009-2011, and it also contains the rank position regarding each indicator.

The FR2 value cannot be directly compared between the data sets, since it has the passenger vehicle kilometers in its denominator for EU-27-that is, occupancy rates were considered; for Brazil, this information is unknown. The data sources for BR-27 are for fatality data (Ministério da Saúde, 2013a), for vehicle fleet (Departamento Nacional de Trânsito, 2013), for population (Ministério da Saúde, 2013b), and for traveled distance (Bastos et al., 2012; Ferraz et al., 2012) for EU-27 data (European Commission, 2013). 
Table 1. Ranking of Mortality and Fatality Rates for BR-27 and EU-27

\begin{tabular}{|c|c|c|c|c|c|c|c|}
\hline \multicolumn{4}{|c|}{ BR-27 } & \multicolumn{4}{|c|}{ EU-27 } \\
\hline DMU & MR & FR1 & FR2 & DMU & MR & FR1 & FR2 \\
\hline AM & $\underset{\left(1^{\mathrm{st}}\right)}{12.90}$ & $\begin{array}{c}8.55 \\
\left(11^{\text {th }}\right)\end{array}$ & $\begin{array}{c}46.68 \\
\left(4^{\text {th }}\right)\end{array}$ & UK & $\begin{array}{c}3.33 \\
(1 \mathrm{st})\end{array}$ & $\underset{\left(3^{\text {tid }}\right)}{0.60}$ & 30.90 \\
\hline PA & $\underset{\left(2^{\text {nd }}\right)}{16.46}$ & 12.88 & $\underset{\left(17^{\mathrm{th}}\right)}{71.96}$ & $\mathrm{SE}$ & $\begin{array}{l}3.37 \\
(2 \mathrm{nd})\end{array}$ & $\underset{\left(2^{\text {nd }}\right)}{0.58}$ & $\underset{\left(1^{s t}\right)}{30.41}$ \\
\hline BA & 16.65 & $\underset{\left(16^{\text {th }}\right)}{10.32}$ & $\underset{\left(16^{\mathrm{th}}\right)}{68.94}$ & $\mathrm{NL}$ & $\begin{array}{c}3.47 \\
\text { (3rd) }\end{array}$ & $\underset{\left(1^{s}\right)}{0.55}$ & $\underset{\left(3^{\text {rd }}\right)}{39.46}$ \\
\hline RJ & 16.67 & $\underset{\left(5^{\mathrm{ln}}\right)}{5.85}$ & $\underbrace{47.32}_{\left(5^{\text {th }}\right)}$ & MT & $\begin{array}{c}4.59 \\
\text { (4th) }\end{array}$ & $\underset{\left(4^{\mathrm{th}}\right)}{0.63}$ & $\begin{array}{c}83.63 \\
\left(14^{\text {th }}\right)\end{array}$ \\
\hline SP & $\underset{\left(5^{\text {th }}\right)}{17.27}$ & $\begin{array}{c}3.49 \\
\left(1^{5 t}\right)\end{array}$ & $\begin{array}{c}32.08 \\
\left(1^{15}\right)\end{array}$ & DK & $\begin{array}{c}4.68 \\
(5 \text { th })\end{array}$ & $\underset{\left(10^{\text {th }}\right)}{0.91}$ & $\begin{array}{c}67.27 \\
\left(10^{\text {th }}\right)\end{array}$ \\
\hline $\mathrm{RN}$ & $\underset{\left(6^{\text {th }}\right)}{18.38}$ & $\underset{\left(9^{\text {th }}\right)}{8.04}$ & $\underset{\left(10^{\text {th }}\right)}{60.17}$ & IE & $\underset{\left(6^{\text {th }}\right)}{4.72}$ & $\underset{\left(11^{\text {th }}\right)}{0.93}$ & $\underset{\left(6^{\text {th }}\right)}{45.02}$ \\
\hline $\mathrm{AP}$ & 19.23 & $\underset{\left(20^{\mathrm{ht}}\right)}{11.03}$ & 56.43 & $\mathrm{DE}$ & $\underset{\left(7^{\text {th }}\right)}{4.81}$ & $\frac{0.77}{\left(7^{\text {th }}\right)}$ & $\underset{\left(4^{\text {th }}\right)}{42.59}$ \\
\hline $\mathrm{AC}$ & $\underset{\left(8^{\text {th }}\right)}{19.34}$ & $\begin{array}{c}9.33 \\
\left(13^{\text {th }}\right)\end{array}$ & $\underset{\left(11^{\mathrm{th}}\right)}{62.81}$ & FI & 5.25 & $\underset{\left(5^{\mathrm{th}}\right)}{0.73}$ & $\underset{\left(5^{\mathrm{t}}\right)}{44.05}$ \\
\hline $\mathrm{RS}$ & $\begin{array}{c}19.52 \\
\left(9^{\text {th }}\right)\end{array}$ & $\begin{array}{l}4.45 \\
\left(2^{\mathrm{nd}}\right)\end{array}$ & 41.02 & ES & $\begin{array}{c}5.26 \\
\left(9^{\text {th }}\right)\end{array}$ & $\underset{\left(6^{\text {th }}\right)}{0.74}$ & $\underset{\left(11^{\text {th }}\right)}{68.97}$ \\
\hline MA & $\underset{\left(10^{\text {th }}\right)}{19.94}$ & $\underset{\left(25^{\mathrm{ht}}\right)}{16.21}$ & $\underset{\left(25^{\text {th }}\right)}{104.68}$ & FR & $\begin{array}{c}6.49 \\
\left(10^{\text {th }}\right)\end{array}$ & $\underset{\left(12^{\mathrm{h}}\right)}{1.01}$ & $\underset{\left(15^{\text {th }}\right)}{90.31}$ \\
\hline PB & $\underset{\left(11^{\text {th }}\right)}{21.28}$ & 11.53 & 82.02 & SK & $\begin{array}{c}6.62 \\
\left(11^{\text {th }}\right)\end{array}$ & $\underbrace{1.78}_{\left(22^{\text {ndd }}\right)}$ & 131.69 \\
\hline PE & $\underset{\left(12^{\text {th }}\right)}{21.46}$ & $\underset{\left(17^{\text {th }}\right)}{10.78}$ & $\underset{\left(22^{\text {nd }}\right)}{85.55}$ & IT & $\begin{array}{c}6.73 \\
\left(12^{\text {th }}\right)\end{array}$ & $\underset{\left(8^{\text {tit }}\right)}{0.81}$ & $\begin{array}{c}54.60 \\
\left(7^{\text {th }}\right)\end{array}$ \\
\hline $\mathrm{MG}$ & $\underset{\left(13^{\text {th }}\right)}{21.70}$ & $\underset{\left(6^{\text {th }}\right)}{6.14}$ & $\underset{\left(6^{\text {(h) }}\right)}{48.61}$ & AT & $\begin{array}{c}6.80 \\
\left(13^{\text {th }}\right)\end{array}$ & $\underset{\left(13^{\text {th }}\right)}{1.02}$ & $\underset{\left(12^{\text {th }}\right)}{76.15}$ \\
\hline $\mathrm{CE}$ & $\underset{\left(14^{4 h}\right)}{22.06}$ & $\underset{\left(18^{\text {th }}\right)}{10.96}$ & $\begin{array}{c}96.46 \\
\left(24^{4 h}\right)\end{array}$ & $\mathrm{EE}$ & $\begin{array}{c}6.89 \\
\left(14^{\mathrm{d}}\right)\end{array}$ & $\begin{array}{c}1.39 \\
\left(19^{\mathrm{hi}}\right)\end{array}$ & $\underset{\left(16^{\mathrm{h}}\right)}{92.27}$ \\
\hline DF & $\underset{\left(15^{\text {th }}\right)}{23.94}$ & $\underset{\left(3^{\text {rd }}\right)}{5.04}$ & $\underset{\left(3^{\text {rd }}\right)}{42.50}$ & $\mathrm{HU}$ & $\underset{\left(15^{\mathrm{di}}\right)}{7.33}$ & $\underset{\left(24^{4 h}\right)}{2.03}$ & 150.05 \\
\hline $\mathrm{AL}$ & $\begin{array}{c}24.73 \\
\left(16^{\text {th }}\right)\end{array}$ & $\underset{\left(27^{\mathrm{h}}\right)}{17.70}$ & $\underset{\left(26^{\text {th }}\right)}{128.19}$ & SI & $\begin{array}{c}7.34 \\
\left(16^{\text {th }}\right)\end{array}$ & $\underset{\left(15^{\text {th }}\right)}{1.21}$ & $\underset{\left(9^{\text {th }}\right)}{58.52}$ \\
\hline SE & $\underset{\left(17^{\text {th }}\right)}{28.43}$ & $\begin{array}{c}14.03 \\
\left(24^{\text {th }}\right)\end{array}$ & $\underset{\left(23^{\text {rd }}\right)}{95.89}$ & LU & $\underset{\left(17^{\text {th }}\right)}{7.50}$ & $\underset{\left(9^{\text {th }}\right)}{0.90}$ & $\underset{\left(8^{\text {th }}\right)}{55.13}$ \\
\hline GO & $\underset{\left(18^{\text {th }}\right)}{30.38}$ & $\begin{array}{c}7.79 \\
\left(8^{\text {th }}\right)\end{array}$ & $\begin{array}{c}57.88 \\
\left(9^{\text {th }}\right)\end{array}$ & $\mathrm{CZ}$ & $\begin{array}{c}7.87 \\
\left(18^{\text {th }}\right)\end{array}$ & $\underset{\left(17^{\mathrm{ht}}\right)}{1.36}$ & $\begin{array}{c}94.05 \\
\left(17^{\text {th }}\right)\end{array}$ \\
\hline $\mathrm{SC}$ & $\underset{\left(19^{\text {th }}\right)}{30.47}$ & $\begin{array}{c}5.66 \\
\left(4^{\text {th }}\right)\end{array}$ & $\underset{\left(7^{\mathrm{th}}\right)}{50.43}$ & $\mathrm{BE}$ & $\begin{array}{c}8.02 \\
\left(19^{\text {th }}\right)\end{array}$ & $\underset{\left(16^{\text {hi }}\right)}{1.35}$ & $\underset{\left(13^{\text {th }}\right)}{77.45}$ \\
\hline $\mathrm{RR}$ & $\begin{array}{c}30.61 \\
\left(20^{\text {th }}\right)\end{array}$ & $\begin{array}{c}10.98 \\
\left(19^{\text {th }}\right)\end{array}$ & $\begin{array}{c}74.45 \\
\left(18^{\text {th }}\right)\end{array}$ & CY & $\begin{array}{c}8.23 \\
\left(20^{\text {th }}\right)\end{array}$ & $\underset{\left(14^{\text {th }}\right)}{1.07}$ & $\begin{array}{c}108.95 \\
\left(21^{s t}\right)\end{array}$ \\
\hline ES & $\begin{array}{c}30.97 \\
\left(21^{s t}\right)\end{array}$ & $\begin{array}{c}8.65 \\
\left(12^{\mathrm{lh}}\right)\end{array}$ & $\begin{array}{c}76.79 \\
\left(20^{\text {th }}\right)\end{array}$ & PT & $\begin{array}{c}8.38 \\
\left(21^{s t}\right)\end{array}$ & $\underset{\left(18^{\text {th }}\right)}{1.37}$ & $\underset{\left(19^{\text {th }}\right)}{103.33}$ \\
\hline PR & $\underset{\left(22^{\text {nd }}\right)}{31.44}$ & $\underset{\left(7^{\text {th }}\right)}{6.53}$ & $\underset{\left(12^{\text {th }}\right)}{63.60}$ & LV & $\begin{array}{c}9.89 \\
\left(22^{\mathrm{nd}}\right)\end{array}$ & $\underset{\left(26^{\mathrm{hb}}\right)}{2.54}$ & $\underset{\left(24^{\text {th }}\right)}{142.66}$ \\
\hline MS & $\underset{\left(23^{\text {rd }}\right)}{32.33}$ & $\begin{array}{c}8.22 \\
\left(10^{\text {th }}\right)\end{array}$ & $\underset{\left(13^{\text {hi }}\right)}{63.61}$ & LT & $\begin{array}{l}9.93 \\
\left(23^{\text {tid }}\right)\end{array}$ & $\frac{1.69}{\left(21^{14}\right)}$ & $\begin{array}{c}98.67 \\
\left(18^{\text {th }}\right)\end{array}$ \\
\hline PI & $\begin{array}{c}32.48 \\
\left(24^{4^{\text {th }}}\right)\end{array}$ & $\underset{\left(26^{\text {th }}\right)}{17.48}$ & $\underset{\left(27^{\text {th }}\right)}{131.41}$ & BG & $\underset{\left(24^{\text {th }}\right)}{10.36}$ & $\underset{\left(25^{\text {th }}\right)}{2.52}$ & 156.55 \\
\hline MT & $\underset{\left(25^{\text {th }^{2}}\right)}{36.35}$ & $\begin{array}{c}9.74 \\
\left(14^{\text {th }}\right)\end{array}$ & $\underset{\left(15^{\text {th }}\right)}{66.62}$ & PL & 11.03 & $\underset{\left(23^{\text {th }}\right)}{1.89}$ & $\underset{\left(23^{\text {td }}\right)}{139.28}$ \\
\hline RO & $\begin{array}{c}36.52 \\
\left(26^{\text {th }}\right)\end{array}$ & $\underset{\left(15^{\text {th }}\right)}{10.13}$ & $\begin{array}{c}66.08 \\
\left(14^{\text {th }}\right)\end{array}$ & RO & 11.17 & $\underset{\left(27^{7 \mathrm{~h}}\right)}{4.70}$ & $\underset{\left(27^{\text {th }}\right)}{306.65}$ \\
\hline TO & $\begin{array}{c}37.12 \\
\left(27^{7^{1}}\right) \\
\end{array}$ & $\begin{array}{c}13.14 \\
\left(23^{\text {dd }}\right) \\
\end{array}$ & $\begin{array}{c}75.66 \\
\left(19^{\text {th }}\right)\end{array}$ & EL & $\underset{\left(27^{\mathrm{h}}\right)}{11.38}$ & $\begin{array}{l}1.60 \\
\left(20^{(\mathrm{h})}\right)\end{array}$ & $\underset{\left(20^{\left(\mathrm{h}^{2}\right.}\right)}{105.04}$ \\
\hline BR-27 & 21.53 & 6.50 & 63.27 & EU-27 & 5.36 & 0.87 & 59.66 \\
\hline
\end{tabular}




\section{APPLICATION AND RESULTS}

\section{Model application and results evaluation}

The ML DEA-CI was computed with the software Lingo, developed by Lindo Systems. An initial form of the MLDEA-CI model was applied to BR-27 and EU-27 data sets. The inserted hierarchical structure is presented in Figure 2. This hierarchy implementation was based on the more similar nature of FR1 and FR2.

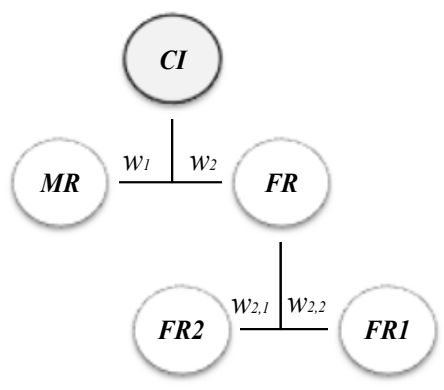

Figure 2. Hierarchical structure used to compute the composite indicator (CI).

To avoid a unilateral weight distribution (that is, the index value being influenced exclusively by MR or FR) but still granting adequate flexibility to the model, the shares $w_{1} * M R$ and $w_{2} * F R$ were limited in the model definition to vary between 10 and 90 percent of the index value. Likewise, to control the weight distribution on FR and avoid an exaggerated weight attribution to either FR1 or FR2 (since they are supposed to present a high association), the weights $w_{2,1}$ and $w_{2,2}$ were allowed to vary within a 20 percent maximum range.

After running the model, it was clear that the EU-27's CIS rank presented a reasonable agreement with the socioeconomic development level of the member countries (see UK, SE, and NL in the first positions and RO, PL, and BG in the last). However, the same trend is much weaker for BR-27, since many less developed states (with inferior road safety standards regarding user's behavior, highway condition and enforcement level) like AM, RN, BA, AP, and AC were allocated in very favorable ranking positions.

To better investigate these relationships, two parameters were selected to quantify the social economic development level: the Gross Domestic Product per capita (GDPC) and the motorization rate (MOTR). Pearson correlation coefficients were computed to measure the correlation between GDP x CIS and MOTR x CIS. Before computing the correlation coefficient, the data were submitted to the Shapiro Wilk normality test and, considering the confidence interval of $95 \%$, they are all considered normally distributed. The computation of these values was preceded by an outlier detection process, in which an unusual GDPC value for the DF (Distrito 
Federal) was found, being almost four standard deviations above the average $\left(\mathrm{z}_{\text {score }}=\right.$ 3.99), and also for LU (Luxembourg) with a $\mathrm{z}_{\text {score }}=3.58$; they were both excluded. No statistically significant correlation was found for the BR-27 data set considering the confidence interval of $95 \%$. For EU-27, statistically significant correlations were obtained: -76 percent for GDP x CIS and 49 percent for MOTR x CIS.

These remarkable differences on the correlation values may be attributed to the distinguished effects on MR, FR1, and FR2 produced by contrasting motorization levels in BR-27 (38 vehicles / 100 inhabitants in average) if compared to the EU-27 (59 vehicles / 100 inhabitants in average). The explanation for such assertion is given as follows. When the GDP per capita and, consequently, the motorization level are significantly low, as is the case for the rapid, but still moderate motorization levels of most Brazilian states (at least when compared to high income road safety best performing countries), a substantial bias may emerge on the "mortality $x$ fatality rates" analysis: the fatalities per inhabitant rate (MR) tends to be directly proportional to the motorization rate, while the fatalities per vehicle or per vehicle kilometers traveled rate (FR1 or FR2) tend to be inversely proportional to the motorization rate. Therefore, quite low correlations between the CIS and the listed socioeconomic parameters could be expected.

Theoretically, as motorization increases, road safety becomes a more evident problem, until the time when its impacts reach unacceptable levels and both society and government effectively react by putting into action measures towards road safety. At a certain stage, a breakdown point is reached, and all three indicators (MR, FR1, and FR2) tend to be inversely proportional to the motorization rate. Such development stage is currently being experienced by most EU-27 countries, which in the last years have managed to reduce their MR, FR1, and FR2. Thus, fairly high correlations between CIS and socioeconomic parameters are expected. This switching behavior in the relationship between mortality and fatality rates along different motorization stages was already stressed in the literature (Elvik et al., 2009; Jørgensen, 2006; Yannis et al., 2011).

To conclude this section, the analysis of results derived from a composite indicator constructed using both MR and FR should be carefully carried out in order not to fall in any pitfall offered by the confounding effect of the motorization rate (affecting the relationship between MR and FR). Thus, the motorization level must be carefully controlled and previously investigated for this type of study; otherwise, the performance of some DMUs may be mistakenly estimated.

\section{Model calibration and results}

Since there is evidence that the model produces more reasonable results for EU-27 than for BR-27 (the reasons were discussed in the previous section), a new 
DEA experiment was planned in order to find a more coherent index score ranking for the BR-27. It consisted of the insertion of an extra weight restriction, now between the shares $w_{1} * M R$ and $w_{2} * F R$, being that $w_{2} * F R$ must be larger than or equal to $1.5^{*} w_{1} * M R$. The intention of this intervention is to reduce the importance attributed to a biased indicator (MR). The 1.5 factor was defined after testing three values: 1.0, 1.5, and 2.0 (differences on CIS values are minimal).

Table 2 presents the rank in the "before and after" calibration stages for BR27 (which, in terms of the states' ranking, it is generally in line with expectations). The influence of the model intervention for the EU-27 data set was very low, and no significant changes occurred in the ranking; thus, the original rank was maintained.

Table 2. OIS and CIS for BR-27 (Before and After Calibration) and EU-27

\begin{tabular}{l|l|l|l|l|l|l|l|l}
\hline \multicolumn{9}{c|}{ BR-27 scores } \\
\hline \multicolumn{2}{c}{ Before calibration } & \multicolumn{2}{c|}{ After calibration } & \multicolumn{3}{c}{ EU-27 scores } \\
\hline DMU & OIS & CIS & DMU & OIS & CIS & DMU & OIS & CIS \\
\hline SP & 1.00 & 1.02 & SP & 1.00 & 1.00 & SE & 1.00 & 1.00 \\
AM & 1.00 & 1.04 & RS & 1.22 & 1.22 & UK & 1.00 & 1.00 \\
RJ & 1.09 & 1.13 & RJ & 1.33 & 1.34 & NL & 1.04 & 1.05 \\
RS & 1.16 & 1.19 & DF & 1.37 & 1.38 & DE & 1.38 & 1.41 \\
RN & 1.28 & 1.32 & AM & 1.41 & 1.43 & IE & 1.43 & 1.45 \\
BA & 1.29 & 1.35 & MG & 1.47 & 1.48 & MT & 1.41 & 1.47 \\
MG & 1.34 & 1.37 & BR-27 & 1.55 & 1.56 & FI & 1.38 & 1.50 \\
BR-27 & 1.35 & 1.39 & SC & 1.64 & 1.65 & DK & 1.45 & 1.52 \\
DF & 1.37 & 1.41 & RN & 1.67 & 1.68 & ES & 1.58 & 1.59 \\
AC & 1.37 & 1.42 & AC & 1.80 & 1.82 & EU-27 & 1.61 & 1.62 \\
PA & 1.33 & 1.43 & AP & 1.82 & 1.85 & IT & 1.65 & 1.88 \\
AP & 1.39 & 1.44 & GO & 1.88 & 1.89 & FR & 1.97 & 2.01 \\
PE & 1.58 & 1.65 & PR & 1.88 & 1.90 & AT & 2.02 & 2.03 \\
PB & 1.58 & 1.65 & BA & 1.88 & 1.91 & LU & 1.78 & 2.07 \\
CE & 1.64 & 1.73 & MS & 2.02 & 2.03 & SI & 2.05 & 2.15 \\
SC & 1.64 & 1.76 & PA & 2.08 & 2.11 & EE & 2.13 & 2.22 \\
MA & 1.66 & 1.83 & ES & 2.19 & 2.20 & BE & 2.39 & 2.40 \\
GO & 1.81 & 1.85 & PE & 2.22 & 2.25 & SK & 2.18 & 2.43 \\
PR & 1.84 & 1.88 & PB & 2.22 & 2.25 & CZ & 2.39 & 2.43 \\
MS & 1.93 & 1.98 & MT & 2.24 & 2.25 & CY & 2.45 & 2.47 \\
ES & 1.92 & 1.98 & RO & 2.27 & 2.28 & PT & 2.53 & 2.58 \\
RR & 1.97 & 2.03 & RR & 2.30 & 2.31 & HU & 2.43 & 2.72 \\
SE & 2.03 & 2.11 & CE & 2.39 & 2.41 & LT & 2.97 & 2.99 \\
AL & 2.01 & 2.19 & TO & 2.59 & 2.61 & EL & 3.10 & 3.29 \\
MT & 2.16 & 2.22 & SE & 2.71 & 2.74 & LV & 3.16 & 3.40 \\
RO & 2.17 & 2.23 & MA & 2.77 & 2.82 & PL & 3.35 & 3.43 \\
TO & 2.32 & 2.39 & AL & 3.27 & 3.31 & BG & 3.30 & 3.54 \\
PI & 2.43 & 2.54 & PI & 3.47 & 3.50 & RO & 4.06 & 4.92 \\
\hline
\end{tabular}


The only best performing DMU is SP, which could reach an index score equal to 1.0 , followed by RS, RJ, and DF. In the calibrated model, the degree of influence related to the MR share of the composite indicator was reduced, presenting a more equilibrated (and realistic) weight distribution: $w_{1} * M R=26 \%$ (from 14 up to $38 \%$ ); $w_{2,1} * F R 1=31 \%$ (from 22 up to $39 \%$ ); and $w_{2,2} * F R 2=43 \%$ (from 30 up to $54 \%$ ). Previously to the calibration, the average MR share was equal to 68 percent (from 14 up to $87 \%$ ). The same correlation tests performed in the previous section were applied again, and the results now show quite similar statistically significant correlation values for both data sets: in BR-27 equal to -70 percent for GDP $x$ CIS and 52 percent for MOTR x CIS; in EU-27 equal to -80 percent for GDP x CIS and 52 percent for MOTR x CIS. Data for RO was not considered for both correlations among the EU-27, since its CIS was classified as an outlier value $\left(z_{\text {score }}=-3.62\right)$. Again, GDPC data for LU and DF were not considered.

The insertion of a new weight restriction contributed to achieve higher correlation coefficients for both BR-27 and EU-27, although the increments for BR27 are much more expressive. Therefore, the produced effects on both sets of DMUs are desirable, and it justifies the inclusion of the weight restrictions on the DEA model used.

\section{CONCLUSIONS AND FUTURE RESEARCH}

This paper describes a set of procedures aiming to complement and improve the application of DEA on ranking DMUs in the road safety field. Remarkable differences in the application of the MLDEA-CI model for EU-27 and BR-27 were identified and required a model calibration process based on auxiliary indicators, producing knowledge to further develop this methodology for Brazil and other developing nations. The motivation for this analysis is the absence of examples of such model applications for a set of DMUs composed by developing countries/states. On the other hand, the advantages of the method for cross-country comparison in Europe are known, and cases of validated applications can be found in the literature.

It is important to mention that the performed analysis is heavily based on the assumption that there is a causal correlation between the socioeconomic indicators considered (in this case, MOTR and GDPC) and the road safety level of a state, as shown in literature. This hypothesis was necessary in order to have a quantitative referential for evaluating the coherence of the obtained rankings for BR-27, otherwise weight restriction procedures and any other interventions on the model would be arbitrary and unsupported. Additionally, although the attempt to reach higher correlations between the model results and the reference indicators

mentioned, the main goal here is not to be as close as possible to a perfect 
correlation. If that was the case, all the efforts on studying possible rank methods would not represent any extra contribution to the road safety field and one could simply base the ranking on one of these socioeconomic indicators. Hence, the correlation analysis has an auxiliary role in the model's performance evaluation.

As expected, the gains in correlation with the auxiliary socioeconomic indicators (and consequently on the ranking's reliability) through the model calibration process were more noteworthy for the BR-27 data set. However, the correlations for the EU-27 data set also increased, although in a more moderate degree. It indicates that the previous investigation of auxiliary indicators is also meaningful in the European context, and this importance might be intensified in case the set of countries is further expanded.

For future research, it would be valuable to invest in cluster analysis using socioeconomic parameters (e.g., motorization rate and GDP per capita) in order to enable a realistic benchmarking process, since an efficacious action towards road safety in a certain state is more likely to generate desirable results in a state containing a similar background. Benchmarking recommendations suggesting that all Brazilian states should base their performance on SP, for example, does not provide realistic or attainable goals for most of the DMUs.

\section{REFERENCES}

Bastos, J.T., Ferraz, A.C.P., Vieira, H., and Bezerra, B.S. (2012). "Geography of traffic fatalities in Brazil." Rev. ANTT, 2 4, 249-265.

Bax, C., Wesemann, P., Gitelman, P., Shen, Y., Goldenbeld, C., Hermans, E., Doveh, E., Hakkert, S., Wegman, F., and Aarts, L. (2012). Developing a Road Safety Index. Deliverable 4.9 of the EC FP7 project DaCoTA.

Cherchye, L., Moesen, W., Rogge, N., Puyenbroeck, T.V., Saisana, M., Saltelli, A., Liska, R., and Tarantola, S. (2006). Creating Composite Indicators with DEA and Robustness Analysis: the case of the Technology Achievement Index (Public Economics Working Paper Series). University of Leuven.

Cooper, W.W., Seiford, L.M., Tone, K. (2000). "The basic CCR model." Data Envelopment Analysis: A Comprehensive Text With Models, Applications, References and Dea-Solver Software. Springer, pp. 21-40.

Departamento Nacional de Trânsito. (2013). Vehicle fleet [Vehicle fleet], $<$ http://www.denatran.gov.br/frota.htm> (June 21, 2013).

Doyle, J., and Green, R. (1994). "Efficiency and cross-efficiency in DEA: Derivations, meanings and uses." J. Oper. Res. Soc. 45, 567.

Elvik, R., Høye, A., Vaa, T., and Sørensen, M. (2009). "Factors contributing to road accidents." The Hanbook of Road Safety Measures. Emerald Group Publishing Limited, 35-80. 
European Commission. (2013). Statistical pocketbooks 2011-2013, $<$ http://ec.europa.eu/transport/facts-fundings/statistics/> (August 26, 2013).

Ferraz, A.C.P., Jr., A.A.R., Bezerra, B.S., Bastos, J.T., and Silva, K.C.R. (2012). Segurança Viária [Road Safety]. Suprema Gráfica e Editora.

Geiger, P. (1969). "Regionalização." [Regionalization] Rev. Bras. Geogr., 1 31, 525.

Hermans, E. (2009). "A methodology for developing a composite road safety performance index for cross-country comparison." $\mathrm{PhD}$ thesis. Hasselt University, Diepenbeek, Belgium.

Hermans, E., Brijs, T., Wets, G., and Vanhoof, K. (2009). "Benchamarking road safety: Lessons to learn from a data envelopment analysis." Accid. Anal. Prev. 41, 174-182.

Institute for Road Safety Research. (2013). SWOV Fact sheet, $<$ http://www.swov.nl/rapport/Factsheets/UK/FS_Risk.pdf $>$ (October 27, 2013).

Instituto Brasileiro de Geografia e Estatística. (1970). Evolução político administrativa [Political and administrative evolution], $<$ http://www.ibge.gov.br/home/geociencias/cartogramas/evolucao.html> (September 16, 2012).

Jørgensen, N.O. (2006). "Traffic safety." Highway and Traffic Engineering in Developing Countries. Taylor \& Francis, 121-138.

Ministério da Saúde. (2013a). Óbitos por causas externas [External causes fatalities], $<$ http://tabnet.datasus.gov.br/cgi/deftohtm.exe?sim/cnv/ext10uf.def $>$ (July 15, 2012).

Ministério da Saúde. (2013b). Estimativas utilizadas pelo TCU [Estimates used by TCU], <http://tabnet.datasus.gov.br/cgi/deftohtm.exe?ibge/cnv/poptpa.def $>$ (July 15, 2012).

Shen, Y., Hermans, E., Brijs, T., and Wets, G. (2013). "Data envelopment analysis for composite indicators: A multiple layer model." Soc. Indic. Res. 114, 739756.

Shen, Y., Hermans, E., Ruan, D., Wets, G., Brijs, T., and Vanhoof, K. (2010). "Evaluating trauma managment performance in Europe: A multiple-layer data envelopment analysis model." Transp. Res. Rec. 2148, 739-756.

Shen, Y., Hermans, E., Ruan, D., Wets, G., Brijs, T., and Vanhoof, K. (2011). "A generalized multiple layer data envelopment analysis model for hierarchical structure assessment: A case study in road safety performance evaluation." Expert Syst. Appl. 38, 15262-15272.

World Health Organization. (2013). WHO. Global status report on road safety, $<\mathrm{http}$ //www.who.int/violence_injury_prevention/road_safety_status/2013/re 
port/en/index.html> (October 29, 2013).

Yannis, G., Antoniou, C., Papadimitriou, E., and Katsochis, D. (2011). "When may road fatalities start to decrease?" J. Safety Res. 42, 17-25. 